Research Article

\title{
Effect of Cobble Content on the Shear Behaviour of Sand-Cobble Mixtures
}

\author{
Chuang Wang, ${ }^{1}$ Jinyu Dong, ${ }^{1}$ Zhiquan Huang $\mathbb{D}^{2}{ }^{2}$ Jianjun Zhou, ${ }^{3}$ and Jihong Yang ${ }^{1}$ \\ ${ }^{1}$ Research Institute of Geotechnical Engineering and Hydraulic Structure, \\ North China University of Water Resources and Electric Power, Zhengzhou 450046, China \\ ${ }^{2}$ Luoyang Institute of Science and Technology, Luoyang 471023, China \\ ${ }^{3}$ State Key Laboratory of Shield Machine and Boring Technology, Zhengzhou 450001, China \\ Correspondence should be addressed to Zhiquan Huang; huangzhiquan@ncwu.edu.cn
}

Received 2 February 2021; Revised 10 March 2021; Accepted 19 March 2021; Published 30 March 2021

Academic Editor: Xun Xi

Copyright (c) 2021 Chuang Wang et al. This is an open access article distributed under the Creative Commons Attribution License, which permits unrestricted use, distribution, and reproduction in any medium, provided the original work is properly cited.

\begin{abstract}
The sand and cobble stratum is a kind of mechanically unstable stratum. Shield machine often encounter problems such as difficulty in excavation, cutterhead wear, and poor slag discharge of the spiral dumper while constructing in this kind of stratum. Considering the complexly and variety of the material composition and structure of this stratum, the sand and cobble stratum in China, Chengdu Subway Line 7, Chadianzi-Yipintianxia Station, was selected to conduct indoor large-scale direct shear tests to systematically study the effects of cobble content (CC) on the shear strength and shear properties of sand and cobble soil. The test results showed that the shear strength and angle of internal friction of sand and cobble soil nonlinearly increased with CC, and the shear strength and angle of internal friction slightly increased when CC was less than $40 \%$. The shear strength and angle of internal friction of sand and cobble soil significantly increased after CC reaching $40 \%$. The shear stress-shear displacement curve has three stages, including the elastic deformation stage, yield stage, and hardening stage. The CC had a control effect on the strength and deformation characteristics of sand and cobble soil. The shear stress-displacement curve of sand and cobble soils with CCs of $20 \%$ and $80 \%$ can be fitted as an exponential model, while the shear stress shear displacement curves of sand and cobble soils with CCs of $40 \%$ and $60 \%$ are hyperbolic. For sand and cobble soil with same CC, the larger the vertical stress is, the larger the normal displacement is.
\end{abstract}

\section{Introduction}

Sand-cobble mixture is widely distributed in the stratum, and its physical and mechanical properties are different from that of sand and intact rock mass. It has the characteristics of higher strength and uneven particle size, which make the high-speed construction and utilization of underground space face many difficulties [1-3]. The more representative underground engineering includes Beijing Subway, Chengdu Subway, and Lanzhou Subway. In the shield tunnelling process, the large shear strength and angle of internal friction induce the problem of the cutterhead, cutter, and spiral excavator severely wearing, and the muck is not easy to discharge $[4,5]$. Therefore, studying the mechanical properties of sand and cobble soil is of great significance to shield machine construction.
Because the sand and cobble soil is a typical loose structure soil, which is very different from cohesive soil, it is difficult to investigate the characteristics of sand and cobble soil, and the related research is limited. By conducting the direct shear test, Li et al. [6] found that the friction angle of sand and cobble soil decreased rapidly with the increase of fine particle content. Hajialilue-Bonab et al. [7] studied the influence of sample size and distribution of grain size on the shear strength of sand and cobble soil through direct shear tests and found that the internal friction angle of the largescale shear test is 6-7 times larger than that of the conventional shear test. Through the large-scale direct shear test, $\mathrm{Xu}$ et al. [8] studied the mechanism of coarse grain content influencing the macroscopic and mesoscopic mechanical properties of gravel soil. Cabalar et al. $[9,10]$ and Monkul et al. [11] conducted a series of direct shear tests or 
oedometer tests on the reconstituted sand-clay mixture and found that there is a close relationship between transition fines content and shear strength or compression performance. Lirer et al. [12] and Eldine et al. [13] conducted largescale triaxial tests on sand and cobble soil. Wu et al. [14] studied the relationship between maximum dry density, optimum moisture content, and coarse particle content of sand and cobble soil through a series of laboratory tests. He et al. [15] and Wang et al. [16] studied the dynamic characteristics of sand and cobble soil through the dynamic triaxial test. Gharahbagh et al. [17] and Peila et al. [18] studied the effect of water content on the slump of sand and cobble soil. Oggeri et al. [19] carried out the slump test of sand and cobble soil under different grain size distributions. Although some studies have been carried out on the strength and dynamic characteristics and fluidity of sand and cobble soil, few studies have been carried out on the changes of sand and cobble soil structure, shear characteristics, and strength under different cobble contents (CCs).

In this study, sand and cobble soil distributed between Chadianzi Station and Yipintianxia Station of Chengdu Metro Line 7 is taken as the research object. Through the indoor large-scale direct shear test of sand and cobble soil with different CCs, the influence of CC on the shear strength and shear characteristics of sand and cobble soil was systematically studied. The research results can provide a reference for shield construction in sandy cobble stratum and have good engineering practical significance.

\section{Laboratory Direct Shear Test of Sand and Cobble Soil}

2.1. Basic Characteristics of Sand and Cobble Soil. The test soil was taken from the Chadianzi -Yipintianxia Station of Chengdu Subway Line 7. According to preliminary survey data [20], the section tunnel is covered with Quaternary Holocene artificial fill, plain fill $\left(\mathrm{Q}_{4}{ }^{\mathrm{ml}}\right)$, Quaternary alluvial clay $\left(\mathrm{Q}_{4}{ }^{\mathrm{al}}\right)$, silty clay, silt; the lower part is Quaternary Upper Pleistocene glacial water sedimentary sandy soil and pebble soil $\left(\mathrm{Q}_{3}{ }^{\mathrm{fgl}+\mathrm{al}}\right)$; the underlying bedrock is Upper Cretaceous Guankou Formation $\left(\mathrm{K}_{2}{ }^{\mathrm{g}}\right)$ mudstone layer. The soil is taken from sandy cobble stratum buried about the depth of 2.5-9.6 m. The lithological components of pebbles and gravels are mainly composed of limestone, granite, and other hard rocks. The general particle size is $2-5 \mathrm{~cm}$, and the maximum particle size is about $18 \mathrm{~cm}$. The pebbles are round or subcircular, with good roundness, poor sorting, poor uniformity, large dispersion, and the great difference in compactness. The pebbles are filled with round gravel and medium-fine sand, with a high content of pebbles and gravel, and the density is $2.27 \mathrm{~g} / \mathrm{cm}^{3}$, and the moisture content is $9 \%$.

The maximum control particle size in the experiment is $80 \mathrm{~mm}$ [21], and the particles larger than $80 \mathrm{~mm}$ are replaced by the equivalent amount of particles with the size of 2-80 $\mathrm{mm}$. According to the code for geotechnical engineering investigation [22], $2 \mathrm{~mm}$ is taken as the boundary particle size of soil and stone, and the percentage of pebble and gravel between $2 \mathrm{~mm}$ and $80 \mathrm{~mm}$ in sand and cobble soil is defined as cobble content (CC) [23-25]. According to the previous survey data, it is found that the particles with the particle size greater than $2 \mathrm{~mm}$ account for about $20-75 \%$, so the CC of the sandy cobble stratum ranges from $20 \%$ to $75 \%$ [20].

2.2. Test Scheme and Instrument. According to the basic characteristics of sand and cobble soil, soil samples with $20 \%, 40 \%, 60 \%$, and $80 \%$ pebbles and gravel content were prepared to study the influence of CC on the actual project deeply; the sample moisture content was $9 \%$. The samples and gradation curves of sand and cobble soil with different CCs are shown in Figures 1 and 2. Large scale direct shear tests were carried out on remoulded samples by using large strain-controlled direct shear apparatus. The sample was $500 \mathrm{~mm}$ in diameter and $400 \mathrm{~mm}$ in height, and the vertical stresses applied by the direct shear test were $100 \mathrm{kPa}$, $200 \mathrm{kPa}$, and $300 \mathrm{kPa}$. The direct shear test used a fast shear method, and the shear velocity was $2 \mathrm{~mm} / \mathrm{min}$. The shearing process proceeded until the horizontal shear strain reached $16 \%$, that is, the relative displacement of the upper and lower shear boxes was $80 \mathrm{~mm}$. The large strain-controlled direct shear apparatus is shown in Figure 3.

\section{Test Results}

3.1. Analysis of the Shear Strength of Sand and Cobble Soil. The shear strength and internal friction angle of sand and cobble soil with different CCs were obtained and are summarized in Table 1. The relationship between the shear strength and CC is shown in Figure 4, and it can be seen that the shear strength changed nonlinearly with the increase of CC, showing a consistent law. The overall trend is that with the increase of CC, shear strength gradually increased. This is similar to the conclusion of Vallejo [26] on the shear strength of soil-rock mixtures.

As shown in Figure 5, the internal friction angle nonlinearly increased with the increase of CC. When CC of sand and cobble soil increased from $20 \%$ to $40 \%$, the internal friction angle increased from $30.43^{\circ}$ to $31.49^{\circ}$ and the friction angle changed little. However, when CC changed from $40 \%$ to $80 \%$, the internal friction angle significantly increased from $31.49^{\circ}$ to $48.3^{\circ}$. According to the construction required for the internal friction angle $\varphi<27^{\circ}$ during shield tunnelling [27], it can be obtained that the shear strength of sand and cobble soil under different CCs does not meet the requirements of shield construction.

The influence of CC on strength indicates the effect of the structural form of sand and cobble soil on shear strength and parameters. With the increase of CC, sand and cobble soil structure gradually changed from a typical suspended dense structure to a skeleton pore structure and finally formed a dense skeleton structure, as shown in Figure 6. There were obvious differences in the shear strength and internal friction angle for different structures, which can be roughly divided into three situations with the change of CC; when CC is $20 \%$, it is in the state of low CC, sand and cobble soil mainly composed of sand, and its 


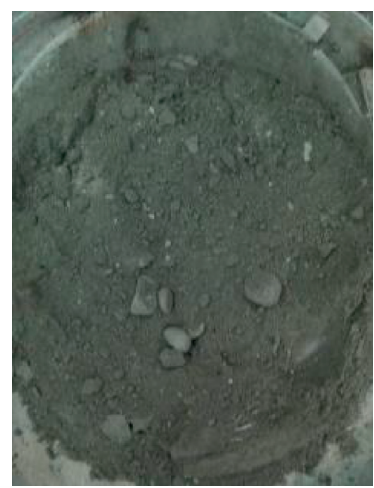

(a)

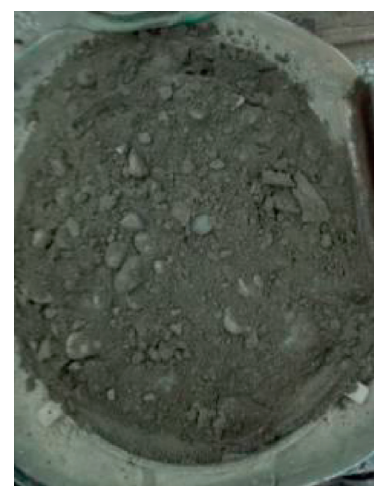

(b)

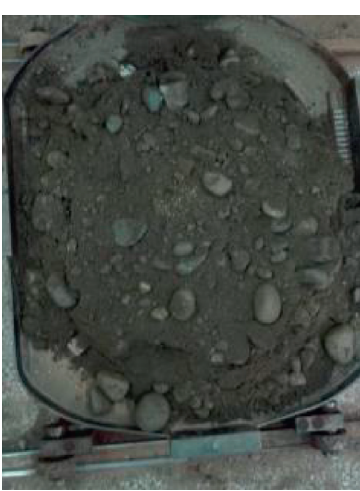

(c)

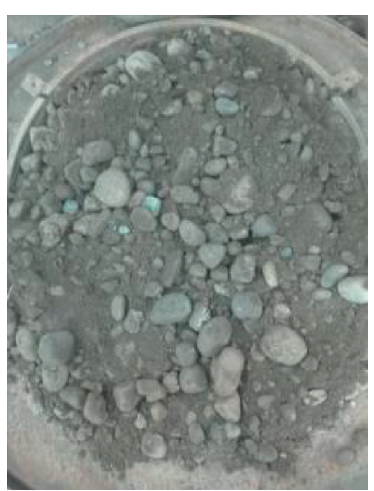

(d)

Figure 1: Samples of sand and cobble soil. (a) CC $=20 \%$. (b) $\mathrm{CC}=40 \%$. (c) $\mathrm{CC}=60 \%$. (d) $\mathrm{CC}=80 \%$.

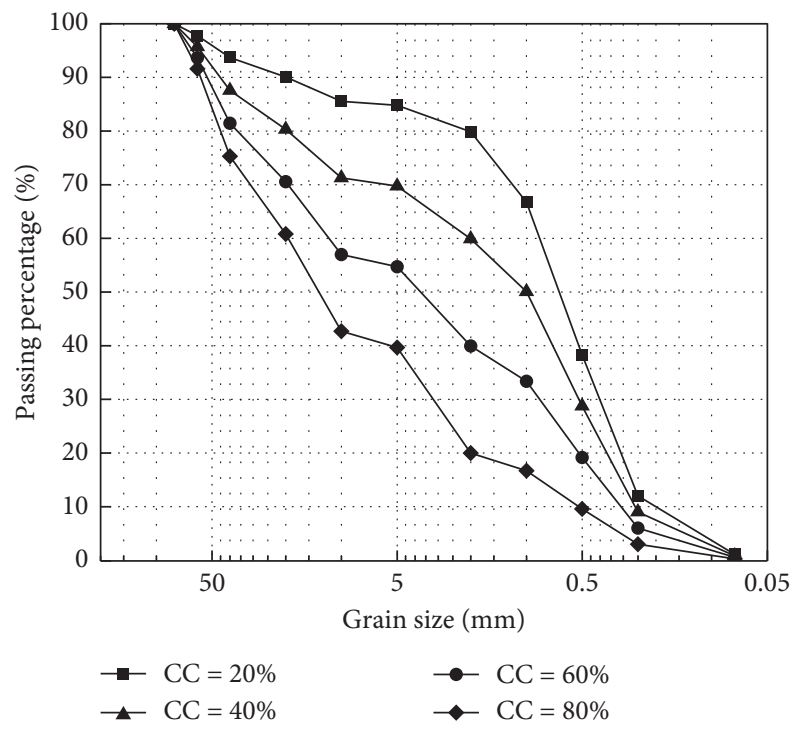

Figure 2: Grain size distribution of sand and cobble soil.

structure is a typical suspended dense structure. The shear strength and internal friction angle mainly depend on the density and the content of the sand [20]; when CC is between $40 \%$ and $60 \%$, it is in the state of medium CC, sand and cobble soil in a skeleton pore structure, and the cobbles play a primary on the shear surface. Under the action of shear force, the soil is destroyed first, and the cobble and gravel contacts and occludes with each other, which increases the friction force obviously. When CC reaches $80 \%$, sand and cobble soil are in a state of high CC, sand and cobble soil have a dense skeleton structure, and the cobbles rub and bite each other under the action of shear force. Similarly, the cobble with low strength is crushed and destroyed, and the high strength plays the role of the skeleton so that the shear strength and internal friction angle of the soil are larger.

3.2. Analysis of the Shear Characteristics of Sand and Cobble Soil. Figure 7 shows the relationship between shear stress and shear strain under three different vertical pressures with

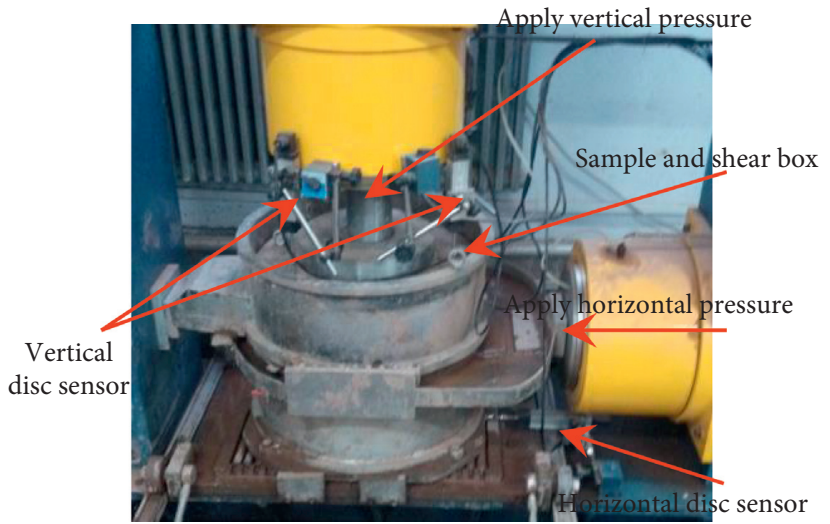

FIGURE 3: Large strain-controlled direct shear apparatus.

different CCs. With the increase of shear displacement, the shear stress increased monotonically, and the shear stress also increased accordingly with the increase of vertical pressure, showing the typical behaviour of loose granular materials. The shape of the shear stress-shear displacement curve of sand and cobble soils with different CCs is basically consistent, which can be clearly divided into three stages: the linear elastic deformation stage, in which the shear stressdisplacement curve is approximately a straight line and the deformation is mainly the compaction [28]. When CC is constant, with the increase of vertical pressure, the cohesion between the cobble and gravel particles is closer, and the occlusive effect is also gradually enhanced, resulting in the longer linear elastic deformation stage. In the yield stage, the slope of the curve changes from steep to flat. In the hardening stage, the deformation is mainly the structural effect produced by interlocking between cobbles and cobbles and between cobbles and sand. The strength increases slightly again due to the occlusion and friction between the cobble and gravel.

At the same time, the shear stress-displacement curve of sand and cobble soil is accompanied by shear "jump" phenomenon [28], and the "jump" phenomenon is gradually significant with the increase of CC (Figure $7(\mathrm{~d})$ ). The breakage and dislocation of the cobbles in the shear process are the main reasons for the phenomenon of "jump," and 
TABLE 1: Shear strength and internal friction angle of sand and cobble soil with different CCs.

\begin{tabular}{|c|c|c|c|}
\hline Cobble content (\%) & Vertical pressure $(\mathrm{kPa})$ & Shear strength $(\mathrm{kPa})$ & Internal friction angle $\left({ }^{\circ}\right)$ \\
\hline \multirow{3}{*}{20} & 100 & 87 & \multirow{3}{*}{30.43} \\
\hline & 200 & 150.5 & \\
\hline & 300 & 216 & \\
\hline \multirow{3}{*}{40} & 100 & 119.5 & \multirow{3}{*}{31.49} \\
\hline & 200 & 165 & \\
\hline & 300 & 232 & \\
\hline \multirow{3}{*}{60} & 100 & 124.5 & \multirow{3}{*}{44.93} \\
\hline & 200 & 200 & \\
\hline & 300 & 320.5 & \\
\hline \multirow{3}{*}{80} & 100 & 144.5 & \multirow{3}{*}{48.3} \\
\hline & 200 & 252 & \\
\hline & 300 & 344 & \\
\hline
\end{tabular}

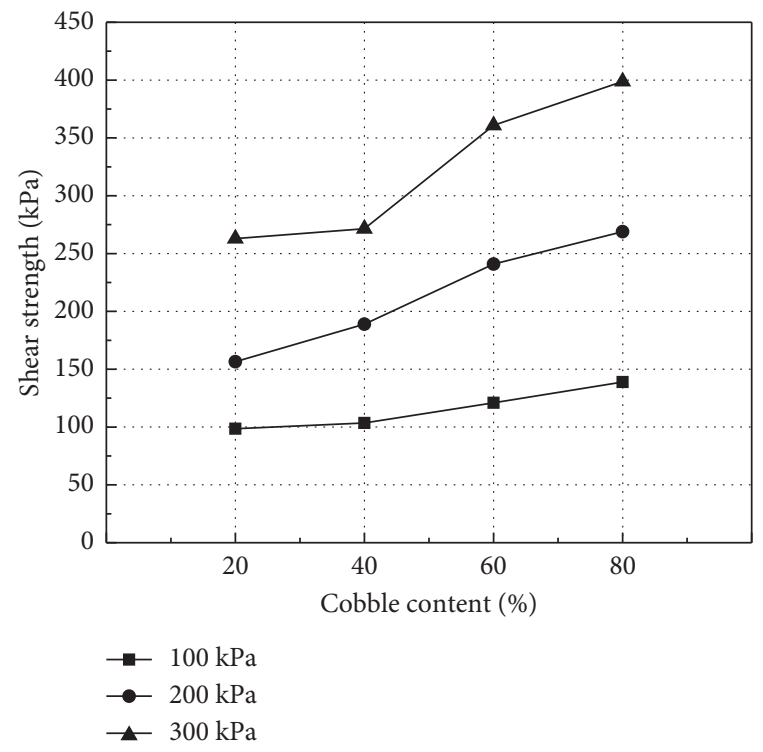

FIgURE 4: Relationship curves of shear strength and cobble content under different vertical pressure.

the higher the CC is, the more frequent the gravel is broken, overturned, and staggered. Moreover, this "jump" is consistent with the "fluctuation" obtained by Cabalar's research [29], so the jump mechanism observed in the experiment can also be attributed to the stick-slip phenomenon [30,31].

In the direct shear test, the hyperbolic and exponential models are commonly used to fit the shear stress-displacement relationship curve, that is, the $\tau$ - $u$ relationship [28]. Taking the sand and cobble soil with different CCs under $300 \mathrm{kPa}$ vertical pressure as an example, the hyperbolic and exponential models are simulated and analyzed. The fitted shear stress-displacement curves of sand and cobble soil with different CCs are given in Table 2 and Figure 8. The shear stress-displacement curves of sand and cobble soil with $20 \%$ and $80 \%$ CC conformed to the result of the exponential model, while the shear stress-displacement curve of sand and cobble soil with $40 \%$ and $60 \%$ CCs more conformed to the result of the hyperbola model, and the correlation coefficients of fitting results are all greater than 0.95 , indicating a good correlation.

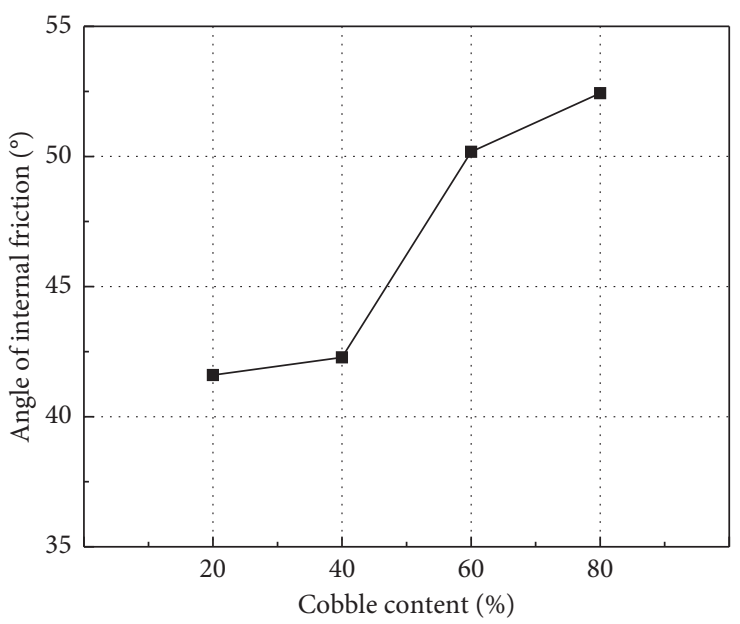

FIGURE 5: Curve of the relationship between the internal friction angle and CC.

Figure 9 shows the normal displacement-shear displacement curve of sand and cobble soil with different CCs under three different vertical pressures. In the shear process, with soil compressed, the normal displacement increased, and the sample volume decreases, showing an obvious shear shrinkage behaviour caused by the relative loose particle arrangement. In the shear process, the dislocation of soil particles filled the original voids, the height of the sample decreased, and the normal displacement increased. Simultaneously, with the increase of vertical pressure, the sample's normal displacement increased more significantly. The normal displacement of sand and cobble soil varied with CC because of sand and cobble soil composed of cobble, gravel, and sand, and CC presented a greater influence on its deformation characteristics. When CC was $20 \%$, sand played the dominant role, and sand and cobble soil tend to behave like sandy soil. Moreover, the vertical deformation increased greatly during the test. When CC was $40 \%$ and $60 \%$, the fine particles in sand and cobble soil were filled in the framework composed of cobbles and gravels. Under lower vertical pressure, the sample was in a relatively dense state. Therefore, the normal displacement slightly increased in the shear process; when CC reached $80 \%$, the proportion of gravel-cobble in sand and cobble soil was relatively high, and 


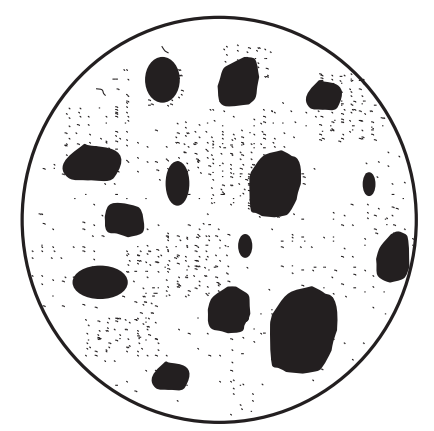

(a)

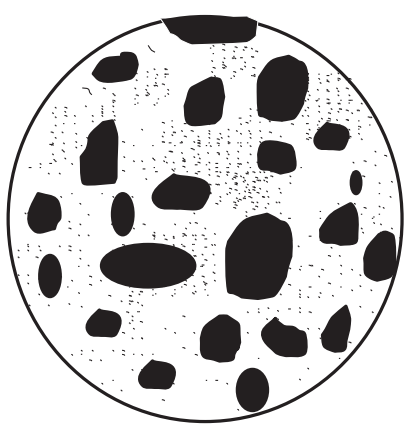

(b)

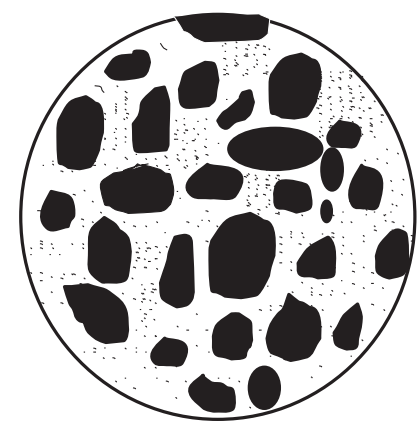

(c)

Figure 6: Composition diagrams of sand and cobble soil with different CCs. (a) Suspension compact structure. (b) Skeleton-pore structure. (c) Dense skeleton structure.
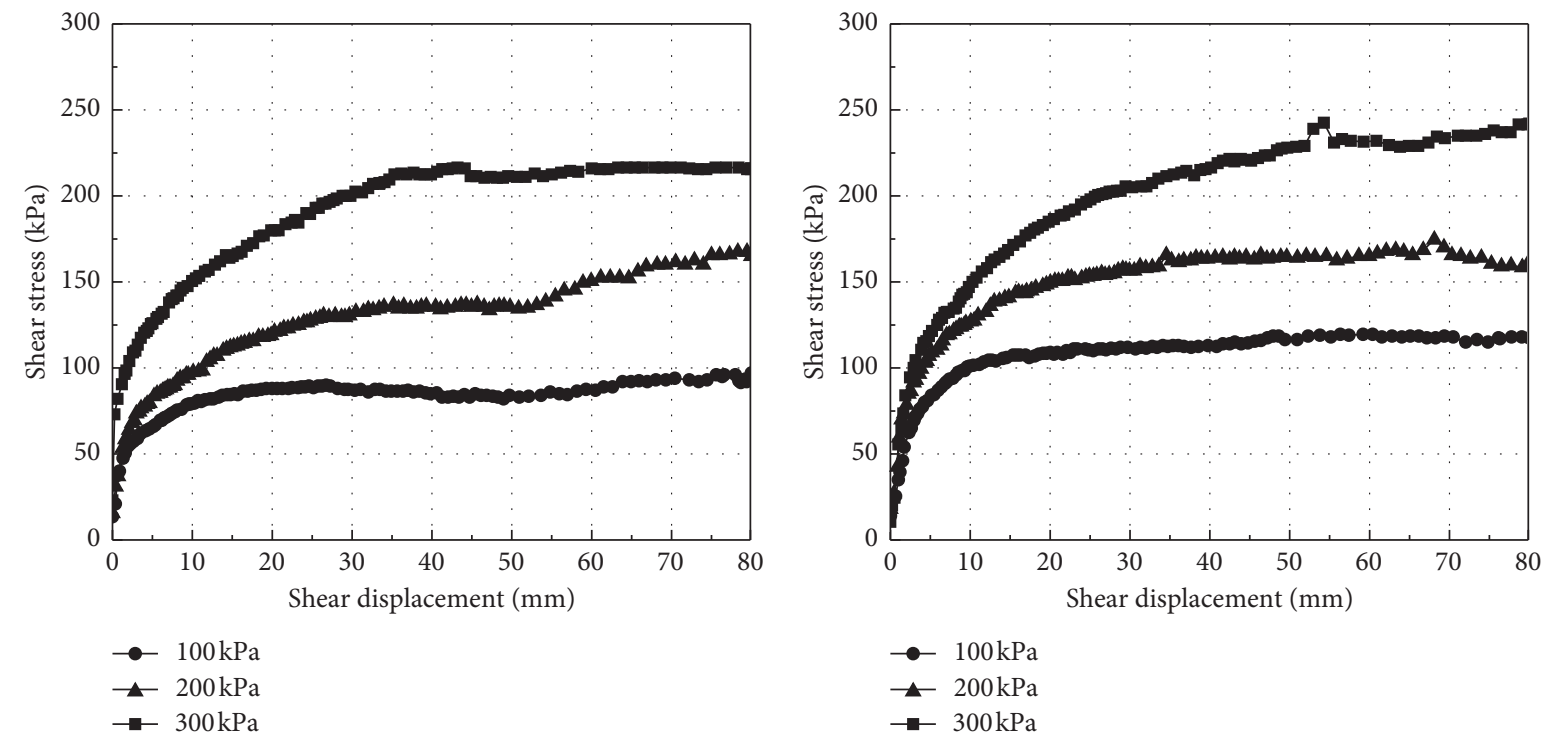

(a)
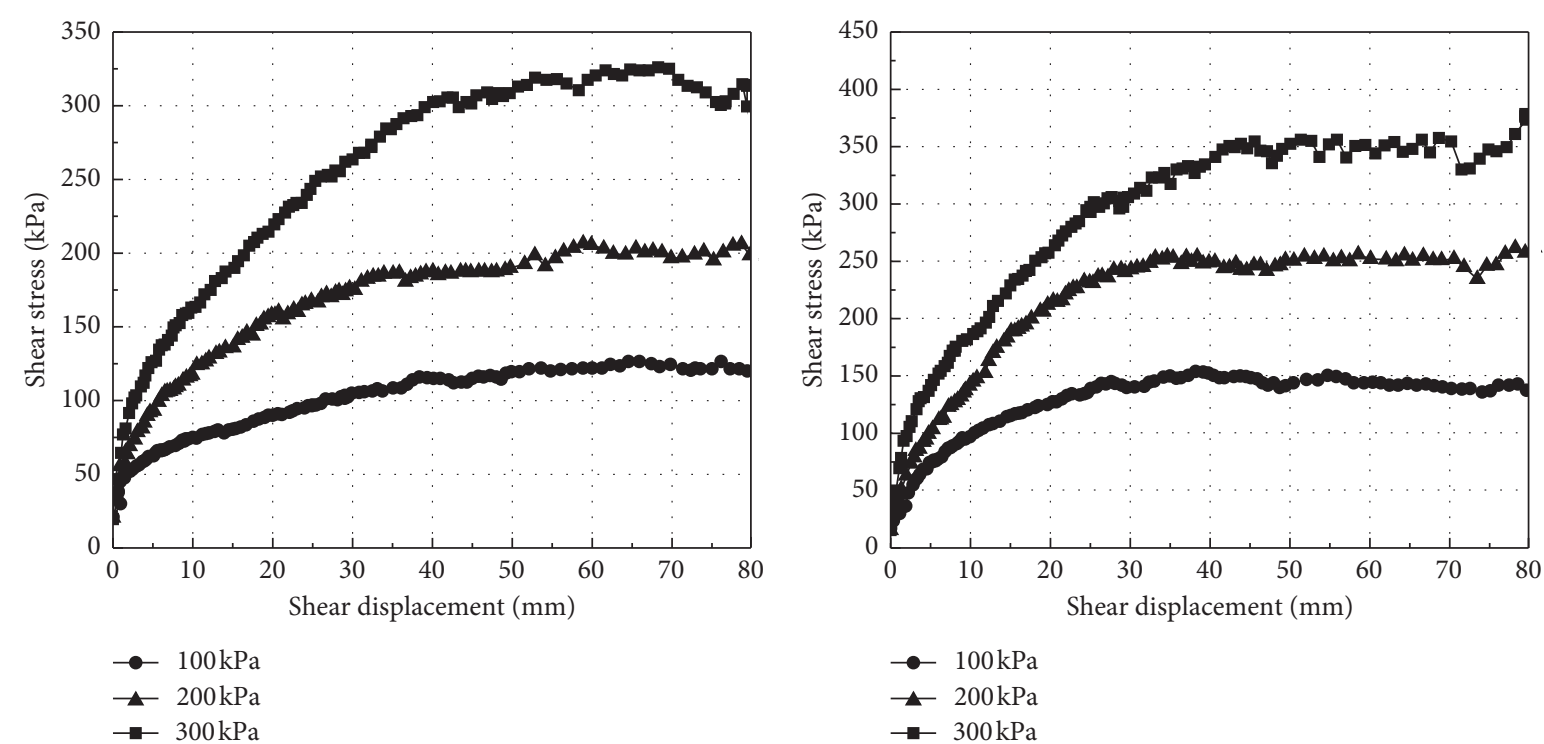

(c)

(d)

Figure 7: Shear stress-shear displacement curve of sand and cobble soil with different CCs. (a) CC $=20 \%$. (b) CC $=40 \%$. (c) CC $=60 \%$. (d) $\mathrm{CC}=80 \%$. 
TABLE 2: Fitting relationship between shear stress and shear displacement of sand and cobble soil with different CCs.

\begin{tabular}{lcc}
\hline Cobble content (\%) & Fitting relationship & Correlation coefficient \\
\hline 20 & $\tau=-139.70 e^{(-u / 13.63)}+216.85$ & 0.977 \\
40 & $\tau=u /(0.0025+(u / 251.25))$ & 0.978 \\
60 & $\tau=u /(0.0031+(u / 368.38))$ & 0.965 \\
80 & $\tau=-307.73 e^{(-u / 17.06)}+361.91$ & 0.989 \\
\hline
\end{tabular}

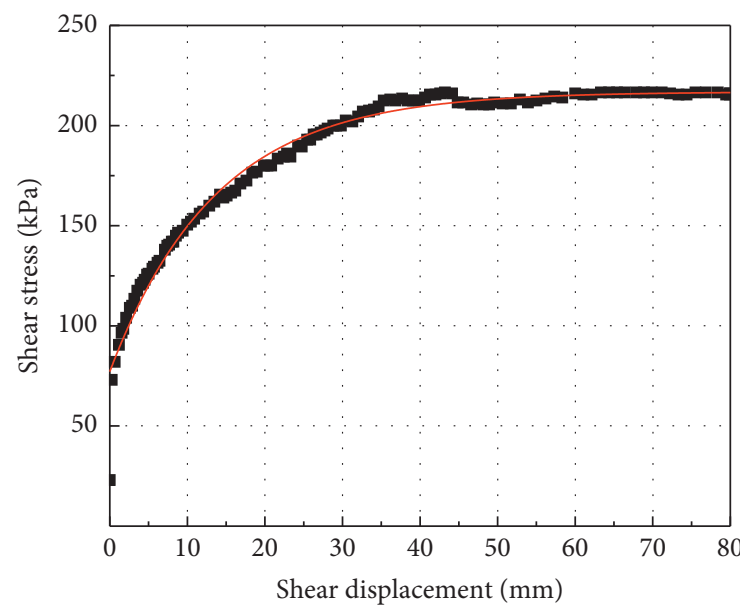

- Test value

- Fitting curve

(a)

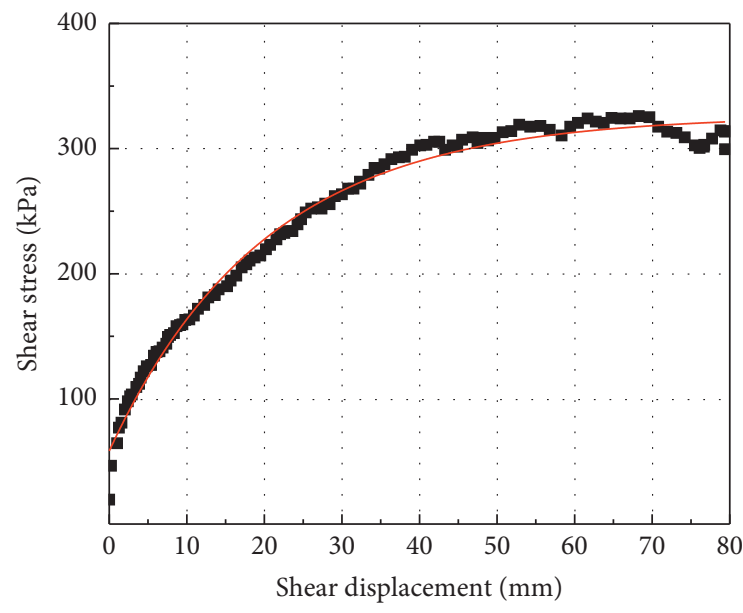

- Test value Fitting curve

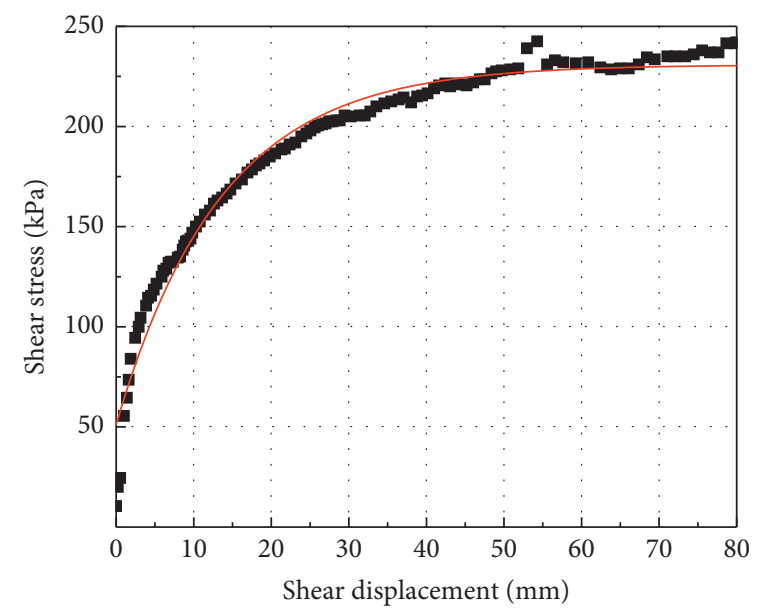

- Test value

Fitting curve

(b)

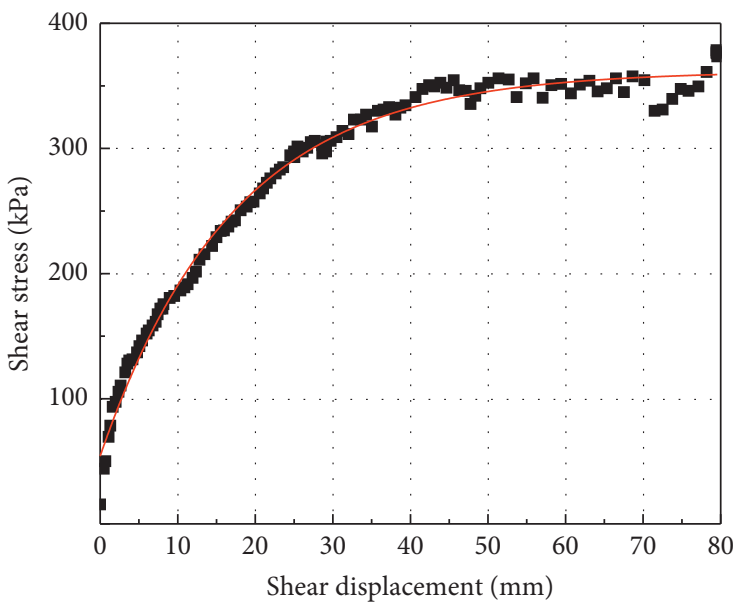

- Test value Fitting curve

(c)

(d)

FIGURE 8: Shear stress-shear displacement fitting curve of sand and cobble soil with different CCs. (a) CC = 20\%. (b) CC = 40\%. (c) CC=60\%. (d) $\mathrm{CC}=80 \%$.

the skeleton of sand and cobble soil was formed by the particles contacting each other. Due to the loose contact between sand and cobble soil particles, coarse particles are easy to shear and stagger deformation in the shear process, making the normal displacement increase significantly in the direct shear test. 


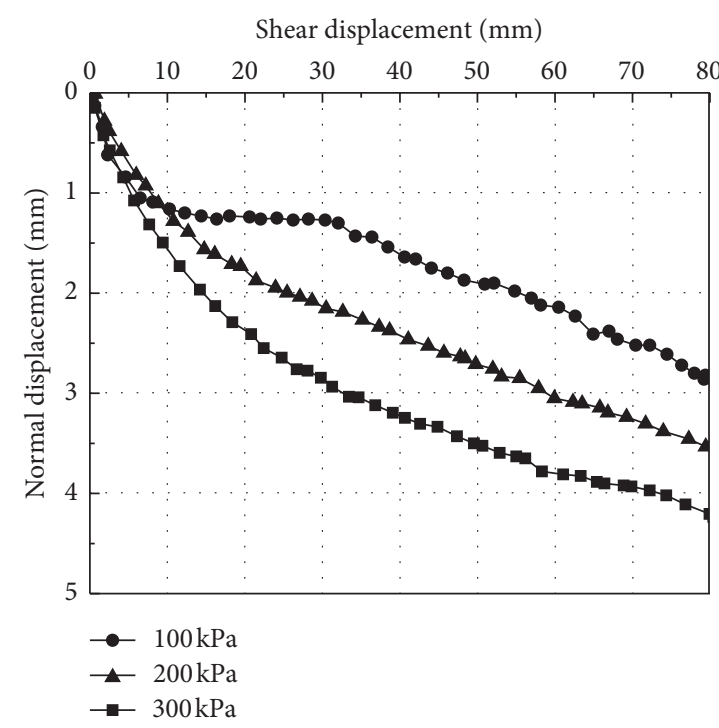

(a)

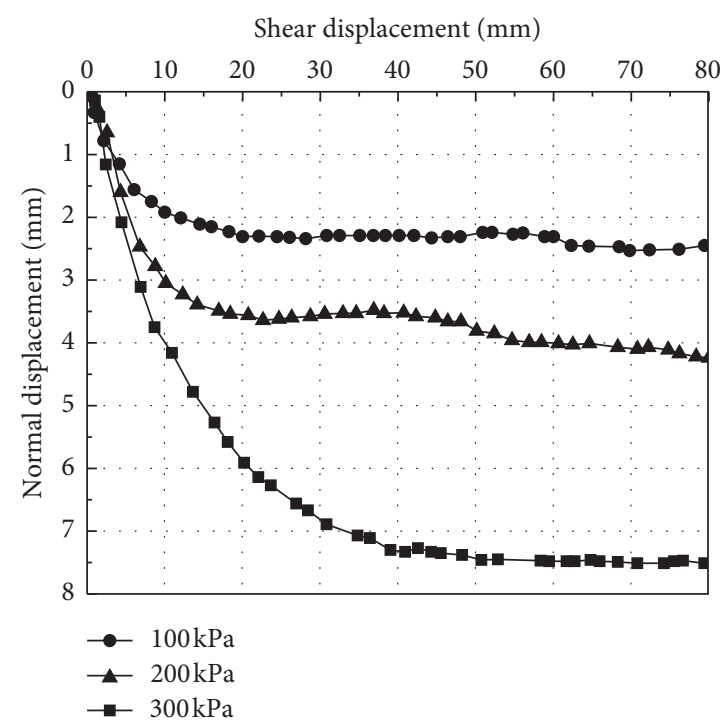

(c)

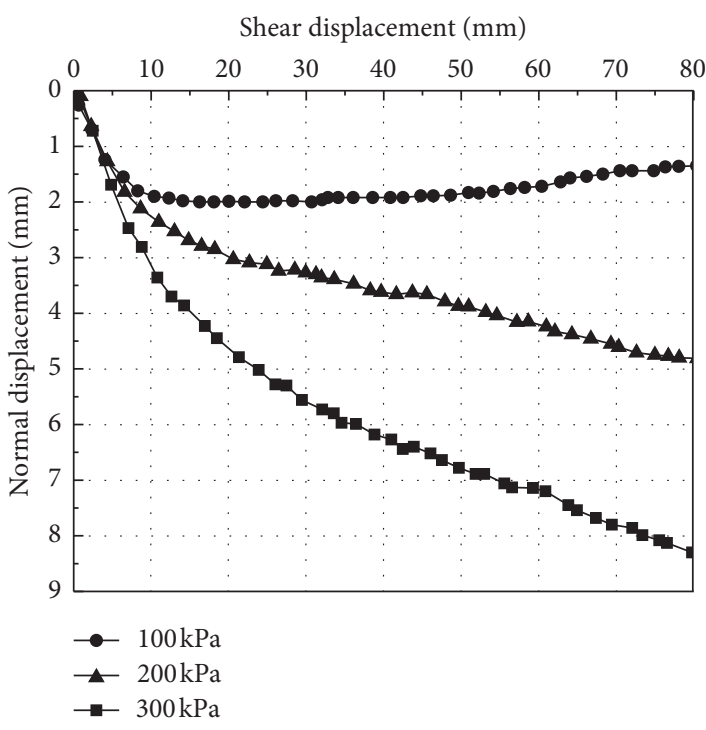

(b)

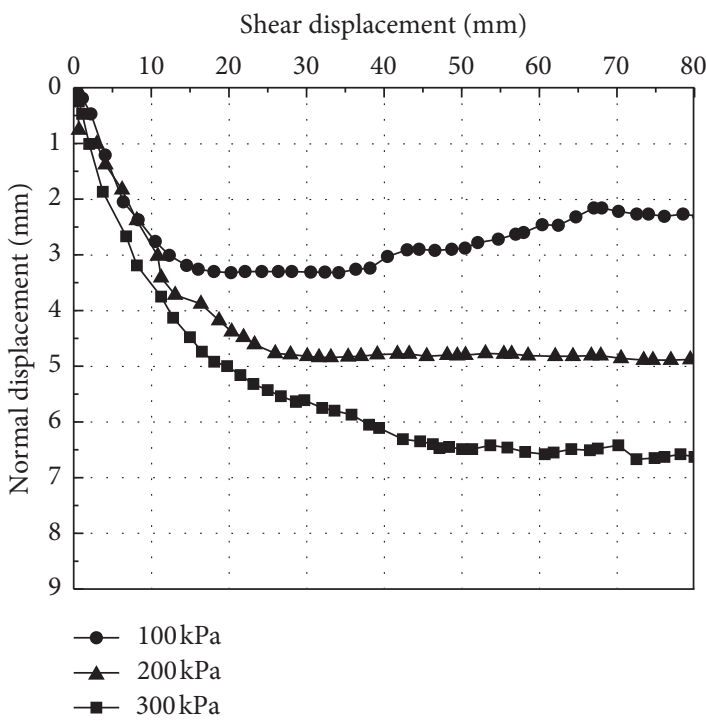

(d)

Figure 9: Normal displacement-shear displacement curve of sand and cobble soil with different CCs. (a) CC $=20 \%$. (b) CC $=40 \%$. (c) CC $=60 \%$. (d) $\mathrm{CC}=80 \%$

\section{Conclusions}

(1) The shear strength and internal friction angle of sand and cobble soil changed nonlinearly with CC. When CC was $20 \%$, sand and cobble soil mainly composed of sand, and its structure was typical suspended dense structure. At this time, the shear strength and internal friction angle were relatively small. When CC was $40 \%$ and $60 \%$, sand and cobble soil formed a skeleton pore structure, and the shear strength and internal friction angle increase significantly with the increase of CC. When CC reached $80 \%$, sand and cobble soil had a dense skeleton structure, and the shear strength and internal friction angle were both larger.

(2) The shear stress-displacement relationship curve in the shear process of sand and cobble soil can be divided into three stages. Moreover, the shear stressdisplacement curves of sand and cobble soil with different CCs show similar change rules, but for the same shear displacement, the larger the CC was, the greater the required shear stress was. At the same time, the results showed that the shear stress-shear displacement curve for $20 \%$ and $80 \%$ CC more conformed to the exponential model, while the shear stress-shear displacement curve for $40 \%$ and $60 \%$ CCs more conformed to the hyperbolic model.

(3) When CC was 20\%, the normal displacement-shear displacement relationship curve continued to change, and the vertical deformation was relatively large. When CC was $40 \%$ and $60 \%$, the sample was relatively dense, and normal displacement was small. 
When CC was $80 \%$, the gravel was broken and dislocated, making the normal displacement significantly increase in the shear process. Simultaneously, when CC was greater than or equal to $60 \%$, the normal displacement-shear displacement relationship curve showed fluctuation, indicating there were dislocation and breakage of the cobble particles during shear.

(4) The shear strength and internal friction angle of sand and cobble soil with different CCs are large, which cannot meet the requirements for shear strength in the process of shield constructing. Therefore, it is necessary to use modifiers to improve the sand and cobble stratum.

\section{Data Availability}

The data used to support the findings of this study are included within the article.

\section{Conflicts of Interest}

The authors declare that there are no conflicts of interest.

\section{Acknowledgments}

The authors wish to thank the Central Plains Science and Technology Innovation Leader Project (214200510030), the Science Foundation of Key Laboratory of Shale Gas and Geoengineering, Institute of Geology and Geophysics, Chinese Academy of Sciences (KLSG201709), the National Key Research and Development Project of China (2019YFC1509704), the National Natural Science Foundation of China (U1704243 and 41741019), and the Henan Province Science and technology research project (192102310006).

\section{References}

[1] X. Du, P. Zhang, and L. Lu, "A multi-scale analysis method for the simulation of tunnel excavation in sandy cobble stratum," Tunnelling and Underground Space Technology, vol. 83, pp. 220-230, 2019.

[2] Q. Yao, H. Di, C. Ji, and S. Zhou, "Ground collapse caused by shield tunneling in sandy cobble stratum and its control measures," Bulletin of Engineering Geology and the Environment, vol. 79, no. 2, pp. 1-16, 2020.

[3] J. J. Zhou, J. P. Song, and S. Z. Tang, "Study on abrasive properties of shielded hob in subway shield of sandy gravel formation," China Civil Engineering Journal, vol. 50, pp. 3135, 2017.

[4] M. Herrenknecht, M. Thewes, and C. Budach, "The development of earth pressure shields: from the beginning to the present/Entwicklung der Erddruckschilde: von den Anfängen bis zur Gegenwart," Geomechanics and Tunnelling, vol. 4, no. 1, pp. 11-35, 2011.

[5] K. Cui and W. K. Lin, "Muck problems in subway shield tunneling in sandy cobble stratum," Polish Maritime Research, vol. 23, pp. 175-179, 2016.
[6] Z. Li and Y. C. Xing, "Effects of dry density and percent fines on shearing strength of sandy cobble and broken stone," Rock and Soil Mechanics, vol. 27, no. 12, pp. 2255-2260, 2006.

[7] M. Hajialilue Bonab, M. Ahmadi-adli, H. Sabetamal, and H. Katebi, "The effects of sample dimension and gradation on shear strength parameters of conditioned soil in EPBM," in Proceedings of the 2009 6th International Symposium on Geotechnical Aspects of Underground Construction in Soft Ground, pp. 295-299, Shanghai, China, April 2008.

[8] X. F. Xu, H. Z. Wei, Q. S. Meng, C. Wei, and Y. H. Li, "DEM simulation on effect of coarse gravel content to direct shear strength and deformation characteristics of coarse-grained soil," Journal of Engineering Geology, vol. 21, no. 2, pp. 311316, 2013.

[9] A. F. Cabalar and R. A. Hasan, "Compressional behaviour of various size/shape sand-clay mixtures with different pore fluids,” Engineering Geology, vol. 164, pp. 36-49, 2013.

[10] A. F. Cabalar and W. S. Mustafa, "Fall cone tests on clay-sand mixtures,” Engineering Geology, vol. 192, pp. 154-165, 2015.

[11] M. M. Monkul and G. Ozden, "Compressional behavior of clayey sand and transition fines content," Engineering Geology, vol. 89, pp. 195-205, 2015.

[12] S. Lirer, A. Flora, and N. C. Consoli, "Experimental evidences of the effect of fibres in reinforcing a sandy gravel," Geotechnical and Geological Engineering, vol. 30, no. 1, pp. 75-83, 2012.

[13] Bassel Self El Dine, J. Claude Dupla, R. Frank, J. Canou, and Y. Kazan, "Mechanical characterization of matrix coarse grained soils with a large-sized triaxial device," Canadian Geotechnical Journal, vol. 47, no. 4, pp. 425-438, 2010.

[14] Y. D. Wu, W. C. Wang, J. Liu, and K. Ji, "Test research on compaction effect of expressway embankment with sandgravel-cobble mixture," Rock and Soil Mechanics, vol. S1, pp. 211-216, 2012.

[15] J. P. He, X. Z. Peng, Y. Zu et al., "Comparative test study on sandy pebble soil static-dynamic behaviors," Journal of Yangtze River Scientific Research Institute, vol. 27, no. 8, pp. 40-43, 2010.

[16] R. H. Wang, B. Jia, A. F. Du, and J. Wang, "Dynamic triaxial testing syudy on dynamic characteristics of sandy pebble soil," Chinese Journal of Rock Mechanics and Engineering, vol. 25, no. 2, pp. 4059-4064, 2006.

[17] E. A. Gharahbagh, J. Rostami, and K. Talebi, "Experimental study of the effect of conditioning on abrasive wear and torque requirement of full face tunneling machines," Tunnelling and Underground Space Technology, vol. 41, pp. 127-136, 2014.

[18] D. Peila, A. Picchio, and A. Chieregato, "Earth pressure balance tunnelling in rock masses: laboratory feasibility study of the conditioning process," Tunnelling and Underground Space Technology, vol. 35, pp. 55-66, 2013.

[19] C. Oggeri, T. M. Fenoglio, and R. Vinai, "Tunnel spoil classification and applicability of lime addition in weak formations for muck reuse," Tunnelling and Underground Space Technology, vol. 44, pp. 97-107, 2014.

[20] Z. Huang, C. Wang, J. Dong, J. Zhou, J. Yang, and Y. Li, "Conditioning experiment on sand and cobble soil for shield tunneling," Tunnelling and Underground Space Technology, vol. 87, pp. 187-194, 2019.

[21] J. Y. Dong, C. Wang, J. J. Zhou, J. H. Yang, and Y. W. Li, "Experimental study of foam-improved sandy gravel soil," Rock and Soil Mechanics, vol. 39, pp. 140-148, 2018.

[22] Ministry of Construction of the People's Republic of China, GB50021-2001 Code for Investigation of Geotechnical 
Engineering, China Architecture and Building Press, Beijing, China, 2002.

[23] X. Xi, Z. Q. Yin, S. T. Yang, and C. Q. Li, "Using artificial neural network to predict the fracture properties of the interfacial transition zone of concrete at the meso-scale," Engineering Fracture Mechanics, vol. 242, Article ID 107488, 2021.

[24] X. Xi, X. Wu, Q. Guo, and M. Cai, "Experimental investigation and numerical simulation on the crack initiation and propagation of rock with pre-existing cracks," IEEE Access, vol. 8, pp. 129636-129644, 2020.

[25] W.-J. Xu and H.-Y. Zhang, "Research on the effect of rock content and sample size on the strength behavior of soil-rock mixture," Bulletin of Engineering Geology and the Environment, vol. 80, no. 3, pp. 2715-2726, 2021.

[26] L. E. Vallejo, "Interpretation of the limits in shear strength in binary granular mixtures," Canadian Geotechnical Journal, vol. 38, no. 5, pp. 1097-1104, 2011.

[27] G. T. Houlsby and S. Psomas, "Soil conditioning for pipejacking and tunnelling: properties of sand/foam mixtures," in Proceedings of the 2001 Underground Construction, pp. 128138, London, UK, 2001.

[28] Z. P. Yang, X. D. Lei, L. Wang et al., "Impact of stone content to shear properties of soil-rock mixture using particle flow code simulation," Journal of Engineering Geology, vol. 25, no. 4, pp. 1035-1045, 2017.

[29] A. F. Cabalar, "Stress fluctuations in granular material response during cyclic direct shear test," Granular Matter, vol. 17, no. 4, pp. 439-446, 2015.

[30] I. Albert, P. Tegzes, B. Kahng et al., "Jamming and fluctuations in granular drag," Physical Review Letters, vol. 84, no. 22, pp. $5122-5125,2000$.

[31] A. Levent Demirel and S. Granick, "Friction fluctuations and friction memory in stick-slip motion," Physical Review Letters, vol. 77, no. 21, pp. 4330-4333, 1996. 